\title{
Saphenous vein as a composite graft from the internal thoracic artery
}

\author{
Ho Young Hwang, Ki-Bong Kim \\ Department of Thoracic and Cardiovascular Surgery, Seoul National University Hospital, Seoul, Korea \\ Correspondence to: Ki-Bong Kim, MD, PhD. Department of Thoracic and Cardiovascular Surgery, Seoul National University Hospital, 101 Daehak- \\ ro, Jongno-gu, Seoul 03080, Korea. Email: kimkb@snu.ac.kr.
}

\begin{abstract}
The saphenous vein (SV) has been used as an aortocoronary bypass graft for coronary artery bypass grafting (CABG) for the past 50 years. However, CABG using the aortocoronary SV has shown disadvantages of lower long-term graft patency rates and subsequently worse clinical outcomes, compared with CABG using the internal thoracic artery (ITA). The advantages of CABG using the ITA prompted interest in total arterial revascularization, using the bilateral ITAs and other arterial conduits as composite graft configurations in patients exhibiting multi-vessel disease. Total arterial revascularization using a Y- or T-composite graft based on the in situ ITA increases the length of the arterial graft and allows the extensive use of arterial conduits to revascularize both the left and right coronary territories. Further, it has demonstrated favorable outcomes in terms of angiographic patency rates, myocardial perfusion and thickening by single photon emission computed tomography, and long-term clinical outcomes. However, previous studies describing the use of the SV conduit as a composite graft have produced conflicting results. In this article, a recent surgical strategy of using the SV as part of a composite graft based on the in situ left ITA will be discussed.
\end{abstract}

Keywords: Coronary artery bypass grafting (CABG); saphenous vein (SV); internal thoracic artery (ITA); composite graft

Submitted Jan 24, 2018. Accepted for publication May 28, 2018.

doi: $10.21037 /$ acs.2018.06.08

View this article at: http://dx.doi.org/10.21037/acs.2018.06.08

\section{Introduction}

The saphenous vein (SV) has been widely used for coronary artery bypass grafting (CABG) since the first planned use of the SV as an aortocoronary bypass graft by Favaloro in 1967 (1). However, neointimal thickening, development of atherosclerosis of the SV conduit, lower patency and worse clinical outcomes have been reported after CABG using the aortocoronary $\mathrm{SV}$ compared with CABG using the internal thoracic artery (ITA) (2-4). Methods to improve patency of the SV conduit include intraoperative pharmacologic treatment using vasodilating agents, postoperative optimal medical therapy such as antiplatelet and lipid-lowering agents, external support devices, intraoperative gene therapy and atraumatic harvesting techniques such as 'minimalmanipulation' or the 'no-touch' technique (5-10). Based on the safety and efficacy of total arterial revascularization using a Y-or T-composite graft connected to the in situ ITA (11-14), the SV has also been used as a composite graft with conflicting results. Herein, a recent surgical strategy of using the SV as part of a composite graft based on the in situ left ITA will be discussed.

\section{Complete revascularization using a composite graft: pros and con}

Advantages such as reduced risk of reintervention and enhanced survival with the use of bilateral ITAs compared with a single ITA have increased interest in total arterial revascularization $(15,16)$. Of total arterial revascularization strategies, construction of composite grafts based on the in situ ITA has advantages such as avoiding aortic manipulation and allowing efficient use of bypass conduits by increasing the graft length. Complete revascularization 
using a skeletonized arterial composite graft could be performed in majority of patients with multi-vessel coronary artery disease when combined with a sequential anastomotic technique $(10,17)$.

There has been a concern that a composite graft based on the in situ ITA may not supply sufficient blood flow to a wider area of myocardium because it only emanates from a single blood source (18). However, other studies have shown that CABG using composite grafts based on the left ITA were comparable with CABG using multiple inflows in terms of angiographic patency, improvement of myocardial perfusion and clinical outcomes (11-14,19-21).

\section{Complete revascularization using a SV composite graft}

Although complete revascularization using an arterial composite graft has been demonstrated to be a safe and efficient method for revascularization (11-14), previous studies describing the use of the $\mathrm{SV}$ as a composite graft have produced conflicting results. One study, which included 25 patients who received an SV composite graft based on the ITA, demonstrated suboptimal shortterm patency (22). Only $72 \%$ of the left ITA grafts were perfectly patent at average 2.5 years after surgery, probably because a large and less reactive SV connected to the ITA created flow diversion from the main stem of the Y graft and rendered the ITA distal to the Y graft more vulnerable to competitive flow. In contrast, other studies demonstrated comparable hemodynamic characteristics, early and midterm patency results between the SV and arterial composite grafts (10,23-25).

One hemodynamic study measured the pressure gradient and fractional flow reserve of composite conduits made with the right ITA or SV based on the in situ left ITA in 17 patients (10 right ITAs vs. 7 SVs patients) (23). Hemodynamics of the right ITA and SV composite grafts were similar in terms of pressure gradients at baseline and hyperemia, and fractional flow reserve. Another recent study measured graft flow using the intraoperative transit time flowmetry at baseline and dobutamine-induced stress, and demonstrated that both the left ITA and SV showed physiological adaptability according to the demand (24). A recent randomized trial comparing results of CABG using the right ITA $v s$. SV composite grafts demonstrated that the SV was non-inferior to the right ITA in terms of 1-year angiographic patency [SV vs. right ITA; 97.1\% (238 of 245 distal anastomoses) vs. $97.1 \%$ (198 of 204), $\mathrm{P}=0.958$ ] and overall $(\mathrm{P}=0.998)$ and MACCE-free survival rates (SV vs. right ITA at 1 and 4 years; $97.3 \%$ and $94.4 \%$, respectively vs. $98.2 \%$ and $91.1 \%$, respectively, $\mathrm{P}=0.597$ ) up to 4 years after surgery when the SV was harvested with a 'minimalmanipulation' technique and used as a composite graft (10). Another retrospective study comparing the results of CABG using SV composite grafts and arterial composite grafts demonstrated that the patency rates of the SV and arterial composite grafts were similar in propensity scorematched groups [SV vs. right ITA; 93.9\% (77 of 82 distal anastomoses) vs. $89.1 \%$ (98 of 110), $\mathrm{P}=0.246] 5$ years after surgery (Figure 1) (25).

Theoretical advantages of SV composite grafts based on the in situ ITA over an aortocoronary bypass graft include: (I) the SV conduit anastomosed to the ITA is exposed to less circulatory stress than a conduit anastomosed to the ascending aorta; (II) the SV composite graft is continuously exposed to endothelium-protective substances such as nitric oxide released from the ITA (10). Complete revascularization using a SV composite graft based on the in situ ITA also has advantages such as avoiding aortic manipulation and allowing efficient use of bypass conduits. The length of the SV needed to reach the target vessel is shorter than that of an aortocoronary SV graft when using a SV composite graft with a sequential anastomosis technique. The SV from a lower or upper leg is sufficient for complete revascularization in most patients with multivessel coronary artery disease. In the randomized trial comparing results of CABG using the right ITA $v s$. SV composite grafts (10), complete revascularization was performed using the SV from a lower leg in 108 of 112 SV group patients (96.4\%), whereas additional conduits to lengthen the right ITA were required in 40 of 112 right ITA group patients (35.7\%).

\section{Conclusions}

Recent studies showed equivalent results between SV and arterial composite grafts in terms of early and mid-term graft patency rates and clinical outcomes. However, there are still concerns regarding the long-term patency of the $\mathrm{SV}$ composite graft, because of pathological changes in $\mathrm{SV}$ grafts, such as neointimal hyperplasia and atherosclerosis, which evolve very slowly over several years postoperatively. Long-term angiographic and clinical follow-up may be needed to demonstrate that the advantages of SV composite grafting are sufficient to overcome the previously published advantages of the right ITA over the $\mathrm{SV}$ as an additional 

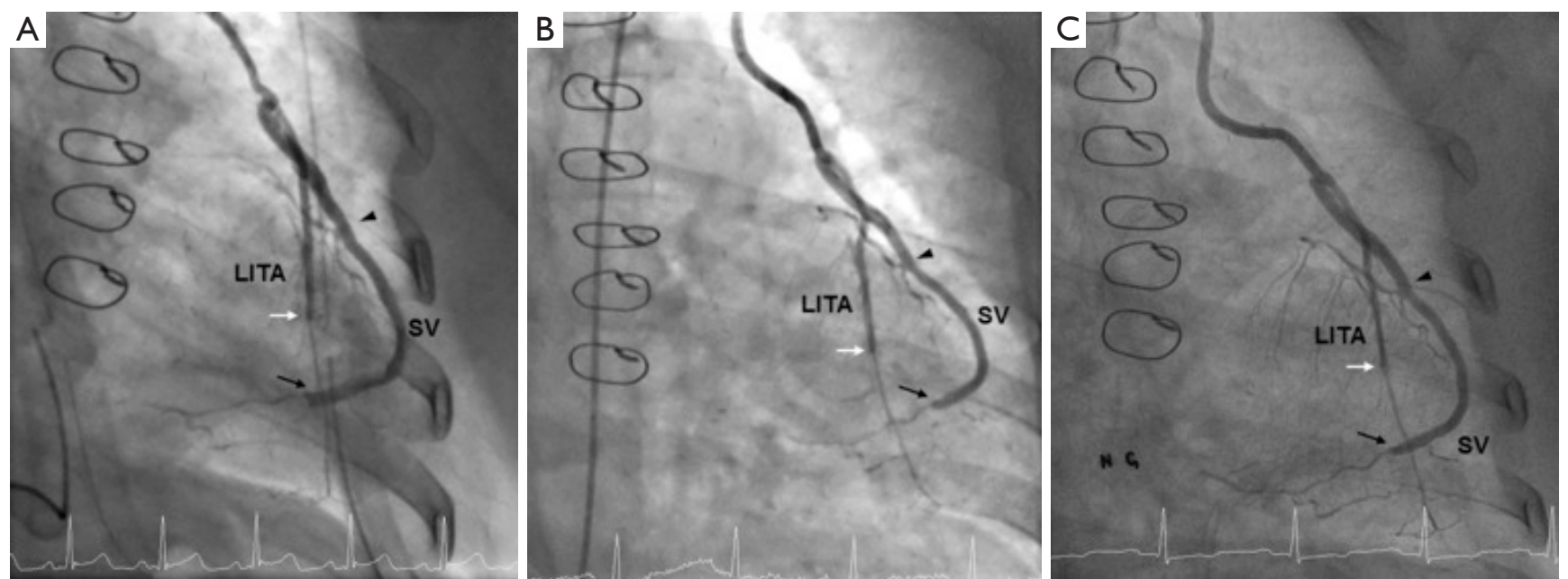

Figure 1 Patent SV Y-composite grafts based on the in situ LITA on (A) early postoperative, (B) 1-year, and (C) 5-year angiograms in a 60-year-old woman. The in situ LITA was anastomosed to the left anterior descending coronary artery (white arrows), and the SV was anastomosed to the diagonal coronary artery (black arrowheads) and obtuse marginal coronary artery (black arrows) using a sequential anastomotic technique [Reprinted from (25) with permission from Elsevier]. SV, saphenous vein; LITA, left internal thoracic artery.

conduit.

\section{Acknowledgements}

None.

\section{Footnote}

Conflicts of Interest: The authors have no conflicts of interest to declare.

\section{References}

1. Favaloro RG. Saphenous vein autograft replacement of severe segmental coronary artery occlusion: operative technique. Ann Thorac Surg 1968;5:334-9.

2. Barboriak JJ, Pintar K, Korns ME. Atherosclerosis in aortocoronary vein grafts. Lancet 1974;2:621-4.

3. Campeau L, Enjalbert M, Lespérance J, et al. Atherosclerosis and late closure of aortocoronary saphenous vein grafts: sequential angiographic studies at 2 weeks, 1 year, 5 to 7 years, and 10 to 12 years after surgery. Circulation 1983;68:II1-7.

4. Loop FD, Lytle BW, Cosgrove DM, et al. Influence of the internal-mammary-artery graft on 10-year survival and other cardiac events. N Engl J Med 1986;314:1-6.

5. Roubos N, Rosenfeldt FL, Richards SM, et al. Improved preservation of saphenous vein grafts by the use of glyceryl trinitrate-verapamil solution during harvesting. Circulation 1995;92:II31-6

6. Post Coronary Artery Bypass Graft Trial Investigators. The effect of aggressive lowering of low-density lipoprotein cholesterol levels and low-dose anticoagulation on obstructive changes in saphenous-vein coronary-artery bypass grafts. N Engl J Med 1997;336:153-62.

7. Taggart DP, Ben Gal Y, Lees B, et al. A randomized trial of external stenting for saphenous vein grafts in coronary artery bypass grafting. Ann Thorac Surg 2015;99:2039-45.

8. Alexander JH, Hafley G, Harrington RA, et al. Efficacy and safety of edifoligide, an E2F transcription factor decoy, for prevention of vein graft failure following coronary artery bypass graft surgery: PREVENT IV: a randomized controlled trial. JAMA 2005;294:2446-54.

9. Souza D. A new no-touch preparation technique. Technical notes. Scand J Thorac Cardiovasc Surg 1996;30:41-4.

10. Kim KB, Hwang HY, Hahn S, et al. A randomized comparison of the SAphenous VEin versus Right Internal Thoracic Artery as a Y-composite graft (SAVE RITA) trial: one-year angiographic results and mid-term clinical outcomes. J Thorac Cardiovasc Surg 2014;148:901-7.

11. Hwang HY, Kim JS, Cho KR, et al. Bilateral internal thoracic artery in situ versus y-composite graftings: five-year angiographic patency and long-term clinical 
outcomes. Ann Thorac Surg 2011;92:579-85.

12. Hwang HY, Cho KR, Kim KB. Equivalency of right internal thoracic artery and right gastroepiploic artery composite grafts: five-year outcomes. Ann Thorac Surg 2013;96:2061-8.

13. Lemma M, Mangini A, Gelpi G, et al. Is it better to use the radial artery as a composite graft? Clinical and angiographic results of aorto-coronary versus Y-graft. Eur J Cardiothorac Surg 2004;26:110-7.

14. Calafiore AM, Contini M, Vitolla G, et al. Bilateral internal thoracic artery grafting: long-term clinical and angiographic results of in situ versus $\mathrm{Y}$ grafts. J Thorac Cardiovasc Surg 2000;120:990-6.

15. Buxton BF, Komeda M, Fuller JA, et al. Bilateral internal thoracic artery grafting may improve outcome of coronary artery surgery. Risk-adjusted survival. Circulation 1998;98:II1-6.

16. Lytle BW, Blackstone EH, Loop FD, et al. Two internal thoracic artery grafts are better than one. J Thorac Cardiovasc Surg 1999;117:855-72.

17. Tector AJ, McDonald ML, Kress DC, et al. Purely internal thoracic artery grafts: outcomes. Ann Thorac Surg 2001;72:450-5.

18. Sakaguchi G, Tadamura E, Ohnaka M, et al. Composite arterial $\mathrm{Y}$ graft has less coronary flow reserve than independent grafts. Ann Thorac Surg 2002;74:493-6.

Cite this article as: Hwang HY, Kim KB. Saphenous vein as a composite graft from the internal thoracic artery. Ann Cardiothorac Surg 2018;7(5):686-689. doi: 10.21037/ acs.2018.06.08
19. Kim KB, Kang CH, Chang WI, et al. Off-pump coronary artery bypass with complete avoidance of aortic manipulation. Ann Thorac Surg 2002;74:S1377-82.

20. Hwang HY, Oh HC, Kim YH, et al. Complete revascularization of the three-vessel territories using a left internal thoracic artery composite graft. Ann Thorac Surg 2015;100:59-66.

21. Kim CY, Hwang HY, Paeng JC, et al. Improved myocardial perfusion and thickening after off-pump revascularization: 5-year follow-up. Ann Thorac Surg 2009;88:1419-25.

22. Gaudino M, Alessandrini F, Pragliola C, et al. Composite $\mathrm{Y}$ internal thoracic artery-saphenous vein grafts: shortterm angiographic results and vasoreactive profile. J Thorac Cardiovasc Surg 2004;127:1139-44.

23. Glineur D, Boodhwani M, Poncelet A, et al. Comparison of fractional flow reserve of composite $\mathrm{Y}$-grafts with saphenous vein or right internal thoracic arteries. J Thorac Cardiovasc Surg 2010;140:639-45.

24. Lobo HG Filho, Lobo JG Filho, Pimentel MD, et al. Intraoperative analysis of flow dynamics in arteriovenous composite Y grafts. Braz J Cardiovasc Surg 2016;31:351-7.

25. Hwang HY, Lee KH, Han JW, et al. Equivalency of saphenous vein and arterial composite grafts: 5-year angiography and midterm clinical follow-up. Ann Thorac Surg 2016;102:580-8. 